\title{
Operação de divisão: possibilidades de intervenção com jogos
}

Sonia Bessa

Universidade Estadual de Goiás

\section{Resumo}

A pesquisa teve como objetivos investigar o nível de compreensão da operação de divisão pelos alunos do $4^{\circ}$ ano do ensino fundamental; realizar intervenção com jogos de regras e desafios específicos para o desenvolvimento da operação de divisão. Fizemos uma intervenção pedagógica com 13 alunos que utilizou o método clínico e foi eficaz na construção da operação de divisão aritmética pelos estudantes que não a possuíam, pois os estudantes apresentaram expressivos progressos nas noções aritméticas. A utilização de jogos e desafios mostrou que podem atender necessidades cognitivas e afetivas dos estudantes.

Palavras-chave: Intervenção pedagógica. Divisão. Jogos. 


\section{Operación de división: posibilidades de intervención con juegos}

\section{Resumen}

La pesquisa objetivó investigar el nivel de comprensión de la división por parte de los alumnos del $4^{\circ}$ grado de la Enseñanza Primaria; y realizar una intervención con juegos de reglas y desafíos específicos para desarrollar la operación de división. La intervención pedagógica realizada con 13 alumnos, utilizó el método clínico y se mostró eficaz en la construcción de la operación de división aritmética que los estudiantes no poseían y cuyos progresos en las nociones aritméticas fueron expresivos. La utilización de juegos y desafíos mostró que pueden atender las necesidades cognitivas y afectivas de los estudiantes.

Palabras clave: Intervención pedagógica. División. Juegos.

\section{Division operation: intervention possibilities with games}

\section{Abstract}

The research aimed to investigate the level of understanding of division by the students of 4th year of elementary school; performing intervention with sets of game rules and specific challenges for the development of the division operation. We have made a pedagogical intervention with 13 students which used the clinical method and was effective in building the arithmetic division operation by students who did not have it, because the students showed significant progress in arithmetic notions. The use of games and challenges showed that they can meet cognitive and affective needs of the students.

Keywords: Educational intervention. Division. Games. 


\section{Opération de division: possibilités d'intervention avec des jeux}

\section{Resumé}

La recherche visait à étudier le niveau de compréhension de la division par les élèves de la 4 e année de l'école élémentaire; effectuer une intervention avec les règles et les défis spécifiques des jeux pour le développement de l'opération de division. Nous avons fait une intervention pédagogique avec 13 étudiants. La méthode clinique utilisée a été efficace dans la construction de l'opération de division arithmétique par les étudiants qui ne l'avaient pas, parce que les étudiants ont montré des progrès significatifs dans les notions arithmétiques. L'utilisation des jeux et des défis a montré qu'ils peuvent répondre aux besoins cognitifs et affectifs des élèves.

Mots-clés: intervention pédagogique. Division. Jeux.

\section{Introdução}

Ao realizar a operação aritmética de divisão, a criança pode valer-se da correspondência para estabelecer a equivalência entre as partes, o esquema de distribuição ou de partir. $O$ aspecto partitivo da divisão é muito presente na vida das pessoas desde cedo, em situações cotidianas e nas brincadeiras das crianças. Esse é um tipo de conhecimento intuitivo, espontâneo, necessário, mas não suficiente para que as crianças compreendam as relações e os termos envolvidos em situações de divisão. Para Correa e Meireles (2000), o aspecto partitivo da operação de divisão e as experiências quotidianas de repartir não podem ser tomadas como sinônimos. Ao repartir, a criança se vale principalmente dos esquemas de correspondência com o objetivo de estabelecer a equivalência entre as partes. Para tal, a criança pode lançar mão apenas de procedimentos de caráter aditivo onde tudo o que necessita fazer, por exemplo, é repetir o mesmo conjunto de ações até que não haja mais elementos disponíveis para uma segunda distribuição. Neste processo, a equivalência é conseguida através da adição ou subtração por tateios de alguns elementos a serem distribuídos.

Ao verificar a criança utilizar os procedimentos aditivos, para estabelecer as equivalências, alguns professores podem tratar a multiplicação como uma simples operação inversa da adição, enquanto o que a criança está fazendo é um procedimento 
intuitivo como já mencionado. Para Nunes e Bryant (1997, p.143) há muito mais na compreensão da multiplicação e divisão do que calcular quantidades: "a criança deve aprender e entender um conjunto inteiramente novo de sentidos do número e um novo conjunto de invariáveis, todas as quais estão relacionadas à multiplicação e à divisão, mas não à adição e à subtração".

Esses mesmos autores falam em raciocínio aditivo e multiplicativo e diferenciam os dois. O raciocínio aditivo se refere a situações nas quais os objetos são reunidos ou separados. Já o raciocínio multiplicativo não envolve essas ações, mas situações de correspondência um-para-muitos, situações que envolvem relações entre variáveis que podem tornar-se mais complexas à medida que o número de variáveis nas situações aumenta e situações que envolvem distribuição, divisão e divisões ao meio.

A distribuição envolve uma nova visão das relações parte todo, que difere de tais relações em situações aditivas. Na distribuição há três valores a serem considerados: o total, o número de receptores e a quota (ou o tamanho da distribuição). A quota e o número de receptores estão em relação inversa um com o outro: enquanto um cresce o outro diminui. A distribuição também envolve um outro tipo de número, as frações. (NUNES; BRYANT, 1997, p.151)

Para Vergnaud (2011), na aprendizagem da multiplicação os alunos são levados a operações de pensamento que não se deixam reduzir a operações numéricas, mas implicam também raciocínios sobre quantidades e grandezas.

Kamii (2002) afirma que colocar objetos em sequência é simples na adição e subtração, porque as crianças podem somar objetos, ou subtrair, repetindo a operação de +1 . $\mathrm{Na}$ multiplicação e na divisão, devem ser contados fatores qualitativos e quantitativos. Para essa autora problemas de divisão requerem um esforço extra na realidade lógicomatemática. "É melhor introduzir problemas de divisão após os alunos terem-se habituado com problemas de multiplicação" (KAMII 2002, p. 123).

Correa e Meireles (2000) investigaram o entendimento intuitivo que crianças de 5 a 7 anos têm da divisão partitiva envolvendo quantidades contínuas em tarefas que tinham que estimar o valor relativo dos quocientes em vez de calcular o seu valor absoluto. Esses autores observaram um progressivo desenvolvimento das habilidades de lidar com a relação de ordem inversa entre divisor e quociente. Os resultados indicaram que a experiência em estabelecer comparações entre partilhas idênticas precede e parece constituir experiência fundamental à criança para a compreensão das relações entre os termos envolvidos na operação de divisão.

A inserção de situações que exigem a divisão equitativa, por exemplo, deve acontecer desde os primeiros anos do ensino fundamental. Kamii (2015, p. 91) defende a inserção de problemas de divisão equitativa em classes de primeiro ao 50 ano do ensino fundamental: "[...] problemas de divisão equitativa podem ajudar as crianças a aprender e compreender as frações." 
Para Morgado, na operação de divisão, encontram-se envolvidas duas estratégias, a de subtração repetida e a de repartição de quantidades; a autora defende que, para solucionar problemas dessa natureza, as crianças utilizam diversos procedimentos: Exemplo: " $25 \div 5$, são $25-5=20-5=15-5=10-5=5$, logo são 5 . Repartição de quantidades consiste em averiguar qual o número de vezes que o divisor é contido pelo dividendo. Exemplo: $30 \div 5$, são $5+5+5+5+5+5$, logo são 6" (MORGADO, 1993, p.69-70).

Para Nunes et al. (2001), o conceito de divisão envolve a compreensão das relações entre os três valores, representados pelo dividendo, pelo divisor e pelo quociente. As crianças precisam compreender que, quanto maior for o número a dividir (divisor), mantendo-se o dividendo constante, menor será o número final (quociente); quanto maior o dividendo, mantendo-se o divisor constante, maior será o quociente.

A compreensão inicial e intuitiva que a criança tem da divisão como o ato de repartir deve progredir; uma vez que a divisão implica em subtração, multiplicação, divisões sucessivas, busca de um quociente, pode ocorrer de não ter um resultado exato ou ainda resultar em frações. Requer considerar simultaneamente o todo e as partes, bem como a relação inversa entre o tamanho e o número das partes.

Para Inhelder e Piaget (1976), os agrupamentos aditivos ou multiplicativos de classes e de relações com suas inferências simples e concretas fundadas sobre a transitividade das inclusões de classes ou de encadeamentos de relações devem progredir para uma combinatória completa que caracteriza o pensamento formal. Essa combinatória cria e estrutura uma lógica de proposições.

Até chegar à lógica das proposições existe um longo caminho a ser percorrido. Duro e Becker (2015) fizeram uma pesquisa com 18 estudantes do ensino médio regular com o intuito de compreender o pensamento combinatório na resolução de situações experimentais. Os autores concluíram que a construção da combinatória passa por patamares de equilíbrio que independem da idade ou série do estudante. $O$ ensino escolar não garante a construção da combinatória, sobretudo se a aprendizagem, dele decorrente, consistiu em uma experiência de memorização mecânica, sem maior significado cognitivo. Esses resultados vêm corroborar o que disseram Inhelder e Piaget (1976, p.39): "[...] combinatória completa é precisamente o que caracteriza o pensamento formal, cuja estrutura ultrapassa os agrupamentos aditivos ou multiplicativos de classes e de relações e cria a estruturação de uma lógica de proposições".

Piaget (1976) já havia previsto quanto à síntese das estruturas anteriores de agrupamento e que ao se tornarem combinatórias, as operações comportam todas as combinações, ou seja, as inversões e as reciprocidades. Comuns ao fechamento do pensamento operatório concreto. 
A operação de divisão aritmética implica no raciocínio multiplicativo (relação divisorquociente) e utiliza o mesmo tipo de estratégia de solução usada na operação de multiplicação - o esquema de correspondência ou o esquema de distribuição. $\mathrm{Na}$ perspectiva da psicologia genética, não basta ao estudante estabelecer equivalência entre subconjuntos, é necessária a coordenação mental das relações envolvidas, o que supõe um processo chamado por Piaget de abstração reflexionante. Piaget (1995, p. 221) afirma que: "a construção da matemática procede por abstrações reflexivas (no duplo sentido de uma projeção sobre novos planos e de uma reconstrução contínua precedendo a novas construções). Toda abstração procede a partir de estruturas mais concretas". Macedo (2014) afirma que se trata de um processo reflexionante, que reflete, que toma consciência das ações realizadas, que reconhece características ou propriedades dos objetos, que faz recortes, cálculos, que cria modelos ou fórmulas, que demonstra. Ao tratar a questão do processo de ensino-aprendizagem, esse autor acrescentou que certos jogos de regras, sob mediação do professor, podem mobilizar aspectos importantes desses processos de abstração reflexionante, que tornam possível a aprendizagem da matemática.

A matemática é um sistema de construções que, apoiado de início nas coordenações das ações e operações do sujeito, faz-se em uma sequência de abstrações reflexionantes de níveis sempre progressivos. A compreensão lógica dos conhecimentos incluindo a operação de multiplicação e divisão é função direta da construção de estruturas mentais. Essa construção obedece a uma sequência invariável, mas pode ocorrer em velocidades diferentes, as quais resultam da qualidade ou frequência das solicitações provenientes dos adultos e das atividades espontâneas das próprias crianças.

Trata-se de um processo inalienável e intransferível. Isso significa que cada pessoa por si própria constrói o conhecimento. Vale dizer que o conhecimento é fruto de uma construção pessoal. [...] resulta de um processo interno de pensamento no decorrer do qual o sujeito coordena diferentes noções entre si, atribuindo-lhes um significado, organizando-as e relacionando-as com outras anteriores (MANTOVANI DE ASSIS et al. 2011, p. 41).

A fim de compreender a complexidade da operação de divisão no contexto da abstração reflexionante, tomar-se-á um exemplo dado por Dayan (2015) considerando a metade de 6 maçãs.

Podería-se pensar que se trata de um problema simples, elementar. Muitas vezes o é, quando a criança o trata, não como um problema de fração, mas sim como um problema de divisão. Muitas vezes é a situação experimental que incita a um tratamento do problema. Por exemplo, quando se trata de dar a metade de seis maçãs a duas bonecas. Aqui, em vez de pensar as seis maçãs como uma totalidade tal que as partes reconstituam o todo e que as partes sejam iguais, a criança pode utilizar um esquema prático, o esquema de repartir e fazer corresponder uma maçã 
a uma boneca, e outra boneca, assim até repartir as seis. Aparentemente a criança resolveu o problema, porém resolveu outro problema: a correspondência termo a termo. Outra maneira de tratar esse problema é considerar as seis maçãs como um todo contínuo, como se as seis maçãs formassem um retângulo. A criança visualiza o meio do retângulo, coloca seu braço sobre ele e separa, de um lado e de outro, de três em três maçãs. Desta maneira, a criança chega também a uma solução correta. Porém é a noção de "meio" que lhe permite encontrar a metade. Muitas outras vezes, pedir a metade de seis maçãs ativa outros esquemas, por exemplo, o esquema de cortar cada maçã. Uma criança pequena pode fazê-lo, podendo também repartir as metades que obteve e chegar a um resultado correto. Pode também, sem chegar à solução correta, mostrar que a metade é a metade de uma só maçã ou ainda pode mostrar todas as metades de todas as maçãs, ou ainda pode indicar que a metade de todas as maçãs são algumas metades.

Uma criança maior de 9 ou 10 anos que proceda da mesma maneira (cortar as maçãs) ver-se-á diante de problemas novos que não esperava e que podem perturbála. Se a criança se coloca problemas novos, e se o resultado de sua própria ação (ter cortado todas as maçãs) a perturba é porque está tratando de resolver outro problema diferente do repartir coisas. A criança coloca o problema de coordenar a participação de cada elemento (maçã) com a participação do conjunto. Assim, esperando encontrar menos quando quer dar a metade, encontra mais, porque ao dividir cada maçã multiplica o número de elementos. Confunde a coisa e o número, a metade e o dobro. Esta confusão faz com que a criança não saiba qual é o valor da unidade: a metade por referência à coisa, ou a metade por referência ao número.

Estes diferentes problemas provêm do fato de que a criança considera um referente duplo, porém não é ainda capaz de coordená-los: a metade em relação a cada elemento e a metade em relação ao conjunto.

Crianças pequenas são capazes de dividir o lanche, ou as figurinhas e até os pontos de um jogo recém-concluído, mas segundo Kamii (2008), Macedo, Petty e Passos (2005) Mantovani de Assis (2013) e Piaget (2013b) esses são conhecimentos espontâneos que fazem parte da vida das crianças. $O$ exemplo citado permite perceber a complexidade da operação de divisão que requer um processo de sucessivas abstrações.

Essa construção não ocorre de modo abrupto, mas implica numa estrutura de grupo que implica na reversibilidade. Essas duas reversibilidades vão implicar na construção das operações lógico-matemáticas. As duas formas de reversibilidade mencionadas por Piaget (2013a) são a reversibilidade por inversão ou negação cuja característica reside em uma operação inversa, composta com a operação direta correspondente, resultado numa anulação: + A - $A=0$ e a reversibilidade por reciprocidade das relações, cuja característica reside em que a operação inicial, composta com a sua recíproca, renda numa equivalência. A reciprocidade é a forma de reversibilidade que caracteriza os agrupamentos de relação. Essas duas formas de reversibilidade atuam isoladamente 
sem a construção de um sistema de conjuntos que permita passar de um conjunto de agrupamentos a outro e compor entre si as transformações inversas e recíprocas. É a invenção da combinatória que permite preencher essa lacuna.

Para realizar a compensação exata entre o número de conjuntos e o de elementos de cada conjunto é necessária uma compensação exata. Os estudantes desenvolvem a capacidade de operar com conjuntos equivalentes, realizando uma compensação exata entre o número de conjuntos e o de elementos de cada conjunto dentro de um mesmo todo. Eles realizam todas as composições possíveis, conservando o todo. É uma coordenação entre o multiplicando, o multiplicador e o resultado final e o dividendo, divisor e quociente. Graças ao pensamento reversível o estudante consegue refazer o caminho inverso das operações e começa a construir conceitos, subordinando o pensamento imagístico, estático ao pensamento operativo que agora opera sobre a realidade, transformando-a. Sem a reversibilidade de pensamento o estudante não compreenderia os processos cognitivos presentes na construção da noção de multiplicação e de divisão aritméticas.

Essas formas de reversibilidade redundam na constituição de uma combinatória que é uma estrutura fundamental, que marca a síntese das estruturas anteriores de "agrupamentos" e o ponto de partida de uma série de novos progressos. Ao se tornarem combinatórias "[...] as novas operações comportam todas as combinações, inclusive, precisamente as inversões e reciprocidades. [...]" (PIAGET; INHELDER, 2011, p. 124). A novidade desse novo sistema demonstra um caráter de síntese ou remate e não há simplesmente justaposição das inversões e reciprocidades, mas uma fusão operatória num todo único, ou seja, cada operação será ao mesmo tempo, a inversa de outra e a recíproca de uma terceira, o que dá quatro transformações: direta, inversa, recíproca e inversa da recíproca, sendo a última ao mesmo tempo, correlativa da primeira. O que verificamos é a interdependência das operações. Cada operação direta de um grupo comporta uma operação inversa (subtração para a adição, divisão para a multiplicação). Sem o elemento agregador da abstração reflexionante essa compreensão por parte do aluno pode não acontecer.

Considerando os pressupostos discutidos, essa investigação teve como objetivos: investigar o nível de compreensão e de condutas de divisão de alunos de $4^{\circ}$ ano do ensino fundamental, numa situação de pré e pós-teste; realizar intervenção com jogos de regras e desafios, específicos para o desenvolvimento da operação de divisão; verificar o nível de evolução na compreensão e nas condutas da operação de divisão. 


\section{Metodologia}

Esse é um estudo de natureza empírica descrito por Campell e Stanley (1979) como um delineamento quase experimental porque não dispõe de um controle. É recomendado para verificar os efeitos de uma determinada intervenção no início e no fim do estudo, e permite trabalhar simultaneamente muitas variáveis.

A descrição desse delineamento é: $01 \times 02$ - aplica-se um pré-teste 01, a um grupo; submete-se esse grupo a uma intervenção pedagógica $X$; e aplica-se, então, um pós-teste 02.01 e 02 significam que o mesmo grupo é avaliado antes e depois do tratamento; diferenças entre 02 e 01 evidenciariam a eficácia (ou ineficácia) do tratamento X.

Nessa investigação para o pré e o pós-teste foi utilizada a prova da operação de multiplicação e divisão de Granell (1983) e o tratamento consiste numa intervenção pedagógica com jogos de regras, desafios e situações problema específicos para o desenvolvimento da operação de divisão.

A amostra intencional foi de 13 estudantes de escola municipal. Participaram crianças de ambos os sexos indicadas pelos professores como apresentando alguma dificuldade de aprendizagem em matemática. Foram 13 estudantes do 40 ano, sendo 10 do sexo masculino e 4 do sexo feminino, todos com 9 anos.

Para o pré e o pós-teste, foi utilizada a "prova da operação de multiplicação e divisão" de Granell (1983) que permite verificar o nível de operação de multiplicação e divisão. Nesse estudo foram considerados apenas os resultados da operação de divisão. Essa atividade é realizada da seguinte maneira: sobre uma mesa, o professor dispõe objetos, simulando uma loja. Cada objeto tem, à sua frente, um cartão com preço que varia de 1 a 9 . Numa caixa, ficam várias fichas, que correspondem ao dinheiro (cada ficha corresponde a $\mathrm{R} \$ 1,00$ ). O professor combina com o estudante que cada ficha vale $R \$ 1,00$ e que o preço marcado no cartão corresponde ao preço de cada objeto. Em seguida, pede-se ao estudante que constate o preço dos objetos e se lhe propõe brincar de comprar e vender, sendo ele o comprador e o professor, o vendedor. São propostas duas situações para os estudantes. O professor entrega para a criança uma determinada quantidade de moedas (18) e pergunta-lhe quantos objetos de um determinado tipo podem ser comprados com aquele dinheiro (não menciona a quantidade de fichas). Se o estudante chegar a uma conclusão correta, ser-lhe-á proposto que pense se, com as mesmas moedas, poderá comprar algum outro objeto, dentre os existentes na loja, de maneira que não lhe sobrem ou faltem moedas. O estudante será avisado de que todos os objetos que poderá comprar deverão ser do mesmo tipo. 
Para avaliar os níveis de construção da operação de divisão, Granell (1983) adotou quatro condutas:

Conduta I - crianças que afirmam não poder comprar nenhuma outra coisa, ou somente objetos que custam $\mathrm{R} \$ \mathrm{I}, 00$ não admitindo a possibilidade de fazer diferentes composições, nem mesmo com conjuntos equivalentes;

Conduta II - crianças que tentam operar com conjuntos equivalentes, mas ainda não existe uma compensação exata entre o número de conjuntos e o de elementos de cada conjunto, dentro do mesmo todo. Parece haver um início de tomada de consciência de que, se comprar mais objetos, terão de ser mais baratos e vice-versa, sem que se chegue a uma quantificação exata. Não percebe a coordenação entre as variáveis: multiplicando, multiplicador e resultado final;

Conduta III - Crianças que não são capazes de fazer antecipações corretas, mas chegam a uma solução, por meio de tentativas que vão desde um tateio assistemático, compreendendo algumas propriedades, até um tateio sistemático, com todas as possibilidades de distribuição do todo;

Conduta IV - Crianças que antecipam as possíveis composições do todo, com os respectivos conjuntos equivalentes, por meio de operações mentais, sem necessariamente se basear em comprovações empíricas.

Todos os 13 estudantes fizeram o pré e o pós-teste. Após o pré-teste, foi realizada intervenção pedagógica. O pré e pós-teste e a intervenção valeram-se do método clínico, também conhecido como método crítico. O método clínico consiste em uma intervenção sistemática do pesquisador em função do que o estudante vai dizendo ou fazendo. Em alguns casos, ele tem de cumprir uma tarefa; em outros, explica um fenômeno. O pesquisador, mediante suas ações ou suas perguntas, procura compreender melhor a maneira como o estudante representa a situação e organiza sua ação. Constitui-se em estabelecer um diálogo utilizando situações experimentais propostas pelo pesquisador, visando explorar os raciocínios das crianças. Consiste em conversar livremente com elas, não se limitando a perguntas fixas e utilizando uma linguagem mais próxima possível da linguagem infantil. Piaget e Szeminska (1981, p. 176) disseram que se trata de um método misto, porque faz uso da observação, da experimentação e de teste ou questionários abertos, consiste em conversar livremente com a pessoa, "[...] ele conserva assim, todas as vantagens de uma conversação adaptada a cada estudante e destinada a permitirIhe o máximo possível de tomada de consciência e de formulação de suas próprias atitudes mentais [...]".

Para o programa de intervenção foram selecionados jogos, desafios e situações problemas adaptados de Kamii (2002 e 2008) e outros autores conforme descrito no quadro 1. Todos os jogos e desafios enfatizaram operações de adição, subtração, multiplicação e divisão, valor posicional, base 10, antecipação e cálculo mental. 
A intervenção consistiu em 13 encontros semanais com duas horas de duração. O trabalho aconteceu em pequenos grupos de dois a três alunos, e no pré e póstestes individualmente com a pesquisadora. Ao final da intervenção foi realizado o pós-teste, com o mesmo instrumento do pré-teste. Os jogos de regras e desafios escolhidos permitiram aos estudantes estabelecer relações e coordenações entre as ações e chegar à dedução lógica e à inferência.

Quadro 1: Jogos e desafios propostos no programa de intervenção

\section{Jogo dos palitos 1 e 2}

Formar figuras com uma quantidade $X$ de palitos, multiplicando ou dividindo (MANTOVANI DE ASSIS, 2013).

Jogo - memória de 10, pegue 10, zigue zague, esconderijo, marcando pontos, prova da corrida, tigous

Ser capaz de realizar somas que totalizem 10 através de diferentes quantidades de cartas (KAMII, 2008).

\section{Pega varetas: situação problema}

Comparar quantidades, estabelecer relações de diferença, relacionar a parte e o todo (MACEDO, PETTY; PASSOS, 2000).

Jogo do buraco e marcando pontos. Partir dos procedimentos de contagem até a multiplicação e divisão (MANTOVANI DE ASSIS, 2013).

\section{Jogo salve}

Realizar as operações aritméticas de adição, subtração, multiplicação e divisão através de cálculo mental (KAMII, 2008).

Jogo de quatro em linha - multiplicação e divisão

Somar, subtrair, multiplicar, dividir e criar estratégia para cobrir quatro números em sequência (KAMII, 2008).

Fonte: organização das pesquisadoras. 


\section{Resultados e discussão}

As situações experimentais propostas na intervenção permitiram aos alunos testarem suas hipóteses, refletirem sobre suas ideias e modificá-las, em especial quando Ihes foi proposto um contra argumento. A contra-argumentação consistiu em apresentar determinada resposta de modo contrário à resposta dada pelo aluno. Os questionamentos e contra-argumentações exigiam dos estudantes organizar suas ações mentalmente, recriando-as e modificando-as, uma vez que privilegiavam as ações dos alunos sobre o objeto do conhecimento. A situação experimental do jogo de regras favoreceu a passagem da ação prática ou física para a ação mental, a passagem do plano concreto para o mundo das hipóteses. $\mathrm{O}$ fato de agirem sobre os objetos ajudou-os na criação de novas perspectivas que serviram de base para novos saberes.

Na tabela 1 estão relacionadas as condutas do pré e pós-teste dos estudantes. Para não incorrer na identificação dos estudantes, optou-se por utilizar somente a letra inicial do nome.

Tabela 1: Condutas de multiplicação em pré e pós-teste

\begin{tabular}{l|l|l|l|l}
\cline { 3 - 4 } Alunos & Ano escolar & Idade & Conduta divisão & Conduta divisão \\
\hline 1. A & $4^{\circ}$ ano & 9 & I & Pós-teste \\
2. B & $4^{\circ}$ ano & 9 & - & II \\
3. C & $4^{\circ}$ ano & 9 & - & III \\
4. D & $4^{\circ}$ ano & 9 & II & III \\
5. FM & $4^{\circ}$ ano & 9 & - & III \\
6. GM & $4^{\circ}$ ano & 9 & I & II \\
7. GC & $4^{\circ}$ ano & 9 & I & II \\
8. I & $4^{\circ}$ ano & 9 & II & II \\
9. JV & $4^{\circ}$ ano & 9 & I & III \\
10. J & $4^{\circ}$ ano & 9 & I & II \\
11. K & $4^{\circ}$ ano & 9 & II & II \\
12. L & $4^{\circ}$ ano & 9 & II & III \\
13. R & $4^{\circ}$ ano & 9 & - & III \\
& & & & II \\
\hline
\end{tabular}

Fonte: dados das pesquisadoras. 
Esses resultados permitem afirmar que no pré-teste nenhum dos estudantes foi capaz de fazer compensação e antecipação, os que apresentaram a conduta II conseguiram realizar correspondências biunívocas, isto é, termo a termo entre o objeto desejado e o valor correspondente do dinheiro, mas, de forma intuitiva, não perceberam a operação "n vezes", e não coordenaram as variáveis implícitas na divisão.

Após a intervenção pedagógica, no pós-teste, verifica-se um quadro bem mais animador. Os estudantes apresentaram expressivos progressos, quanto à operação de divisão. Houve uma significativa evolução das condutas do pré ao pós-teste.

No pré-teste, 5 estudantes estavam na conduta mais elementar, ou seja, a conduta I e quatro estudantes não conseguiram concluir a atividade. A conduta I corresponde às crianças que afirmam não poder comprar nenhuma outra coisa, ou somente objetos que custam $R$ \$ I,00 não admitindo a possibilidade de fazer diferentes composições, nem mesmo com conjuntos equivalentes. Somando-se o número dos estudantes da conduta I com o número daqueles que não conseguiram concluir a atividade, verificouse que 9 estudantes do universo de 13 tiveram muita dificuldade na operação de divisão.

Somente 4 estudantes alcançaram a conduta II que ainda é muito elementar. São aquelas crianças que tentaram operar com conjuntos equivalentes, mas ainda não existia uma compensação exata entre o número de conjuntos e o número de elementos de cada conjunto dentro do mesmo todo. Parece haver um início de tomada de consciência de que se comprarem mais objetos, têm de ser mais baratos e vice-versa, sem que se chegue a uma quantificação exata. Os estudantes não percebiam a necessidade de coordenação entre as três variáveis: multiplicando, multiplicador e resultado final. Utilizavam procedimentos empíricos para alcançar os resultados, tinham dificuldade em perceber as possibilidades de distribuição do todo, característico da operação de divisão, não faziam antecipações com ou sem suporte empírico.

No pós-teste após a intervenção pedagógica a evolução foi visível. Dos 5 estudantes que estavam na conduta I, e dos 4 que não conseguiram concluir a atividade, todos evoluíram para melhores condutas. Os outros 4 que estavam na conduta Il evoluíram para a conduta III. No pós-teste 6 conseguiram chegar à conduta III. Nessa conduta a criança ainda não é capaz de fazer antecipações corretas, mas chega a uma solução por meio de tentativas que podem começar desde um tateio assistemático, compreendendo algumas propriedades, até um tateio sistemático, com todas as possibilidades de distribuição do todo.

No pré-teste nenhum dos estudantes encontrava-se nesse nível, portanto houve uma significativa evolução nas condutas da divisão para os alunos que participaram da intervenção pedagógica. Ou seja, quase a metade da amostra chegou a essa conduta. Nenhum dos estudantes chegou à conduta IV da divisão, que corresponde às crianças que antecipam as possíveis composições do todo com os respectivos conjuntos 
equivalentes por meio de operações mentais, sem necessariamente se basear em comprovações empíricas. É possível que o número de intervenções não tenha sido suficiente. Os resultados permitem verificar que todos os estudantes (100\%) evoluíram para melhores condutas de divisão. Houve uma melhor compreensão da operação de divisão. A intervenção mostrou-se eficaz quanto a melhores condutas de divisão. É possível que outros fatores como atendimento individual e personalizado da pesquisadora e a interação social entre os demais estudantes tenha contribuído para essa significativa evolução.

Tabela 2 - resultados do pré e pós-teste da divisão

\begin{tabular}{l|l|l}
\hline Condutas da divisão & Pré teste & Pós teste \\
Conduta 1 & 5 & - \\
Conduta 2 & 4 & 7 \\
Conduta 3 & - & 6 \\
Conduta 4 & - & - \\
Não concluiu a prova & 4 & \\
\hline
\end{tabular}

Fonte: dados elaborados pelas pesquisadoras.

A seguir descrever-se-á a intervenção com alguns dos estudantes. Foram quatro condutas propostas por Granel (1983). Essas condutas estão relacionadas à operação de divisão. Pode ocorrer de o aluno estar em diferentes condutas quando averiguadas outras operações, não avaliadas aqui. Os resultados encontrados permitem verificar as condutas da operação de divisão. É possível que essas condutas possam ser encontradas em outras áreas do conhecimento, contudo somente a operação de divisão foi analisada.

Os trechos destacados em negrito ao longo do texto representam parte das falas dos estudantes que participaram da intervenção.

Iniciada a intervenção com os estudantes do $4^{\circ}$ ano verificou-se que esses tinham muita dificuldade até mesmo com a quantificação e a relação termo a termo dos elementos.

Como o nível de dificuldade inicial dos estudantes era muito acentuado, decidiu-se retomar alguns conceitos básicos como a construção do número, cálculo mental, contagem e numeração, valor posicional e operações de adição e subtração com números de 1 a 10. Foram selecionados alguns jogos de regras que favorecessem essas construções, como o jogo "marcando pontos" que explora as relações numéricas 
de 1 a 5, os jogos de tabuleiro como o "esconderijo", "prova da corrida", "zigue zague" e "paraquedas". Os jogos "pegue 10", "encontre 10", "memória de 10" e "desça 10" apelam para a construção das dezenas, relações numéricas e valor posicional. Esses jogos, com ênfase na unidade e dezena simultaneamente, auxiliaram na retomada dos conceitos básicos de adição, subtração e cálculo mental com números de 1 a 10. Todos os jogos mencionados são de autoria de Kamii (2002 e 2008), e foram adaptados para essa ocasião pelas pesquisadoras.

Inicialmente, todos os estudantes apresentaram muita dificuldade em realizar operações bem elementares como $2+2$ ou $5+5$ ou até mesmo $5+1$ nas situações de jogos. Eles foram alertados que eram livres para usar materiais de contagem como fichas, palitos ou qualquer outra coisa que quisessem. Quase todos os estudantes preferiram usar os dedos, quando o número ficava maior recorriam às marcas de contagem. Um dos estudantes desenhou 12 "tracinhos" (marcas de contagem) em seguida escreveu $12+12+12+12$. Quando perguntado por que fez as marcas de contagem, respondeu que era para não esquecer quantos 12 ele precisava somar.

Alguns estudantes recorriam aos dedos e marcas de contagem ao mesmo tempo. Uns poucos recorreram aos palitos e faziam a correspondência do número de palitos com o número de pontos que deveriam somar, para continuar o jogo.

Kamii (2008), afirma que esse é um procedimento normal quando os estudantes ainda não conseguem perceber a inclusão hierárquica que é a capacidade mental de incluir "um" em "dois", "dois" em "três", e assim sucessivamente. É como se o todo não existisse, elas conseguem até pensar no todo, mas não quando estão pensando nas partes. "[...] Para comparar o todo com a parte, o estudante tem que executar duas ações mentais ao mesmo tempo - dividir o todo em duas partes e fazer com que essas duas partes voltem a formar o todo [...]" (KAMII, 2008, p.16). Faltou aos estudantes a reversibilidade do pensamento, conforme descrita por Piaget (2013a).

As crianças do quarto ano utilizavam com destreza os algoritmos das quatro operações, contudo pelos resultados verificados no pré-teste, é possível que o conhecimento e uso dos algoritmos não garantiram a compreensão das operações.

Os estudantes não percebiam a conservação lógica, nem a coordenação entre o todo e as partes. O longo tempo utilizando o algoritmo de forma mecânica e destituída de compreensão pode ter contribuído para a não compreensão das operações. "A conservação do número não é abstraída dos objetos, pois para chegar a essa operação o estudante precisa basear o seu julgamento num raciocínio dedutivo que supõe a coordenação de suas próprias ações" (MANTOVANI DE ASSIS, 2013, p. 79). Ao trabalhar com os jogos de regras e desafios, saindo do plano concreto para chegar ao abstrato, os estudantes foram paulatinamente compreendendo os processos implícitos nas operações. 
Até a sexta intervenção foram priorizados jogos com ênfase em adição, subtração, cálculo mental e relações numéricas com os números de 1 a 10 . A partir da sétima intervenção foram introduzidos jogos envolvendo os conceitos de multiplicação e divisão.

Compreender a multiplicação é condição necessária, porém não suficiente, para compreender a divisão; essas operações relacionam-se na reversibilidade do pensamento, que permite, ao aluno, coordenar as variáveis: multiplicando, multiplicador e resultado final. Para Piaget (2013a, p. 76) essa reversibilidade é "[...] sem dúvida, o caráter mais específico da inteligência"; de posse da reversibilidade de pensamento, o aluno pode "[...] construir hipóteses e, em seguida descartá-las para retornar ao ponto de partida, percorrer um caminho e refazer o caminho inverso sem modificar as noções utilizadas" (idem, p. 77). A reversibilidade caracteriza, não só os estados de equilíbrio finais, mas ainda os próprios processos evolutivos.

A reversibilidade é a capacidade do estudante de raciocinar retrospectivamente e prospectivamente no tempo. Segundo Lacombe, (2002) esse é um dos primeiros indicadores do pensamento operatório concreto. O estudante torna-se capaz de estabelecer relações objetivas de semelhança e diferença, que possibilitam a classificação e a ordenação de objetos, isso marca a construção da reversibilidade. .

Observe-se o caso de "B" que no pré-teste estava na conduta I da divisão, e no pós-teste foi para a conduta III.

- "B" - Vou lhe vender este carrinho. Coloque aqui o dinheiro suficiente para comprá-lo.

- R\$ 3.

- Quanto você pagou por ele?

- R\$3. (Recolho este objeto e coloco 4 carrinhos).

- Coloque o dinheiro necessário para comprar todos esses carrinhos.

$-\mathrm{R} \$ 12$.

- Quanto dinheiro tem aí?

- R\$ 12.

- Como é que você sabe que precisa de todo esse dinheiro para comprar esses objetos?

- Fiz 4 × $3=12$.

- E agora o que você gostaria de comprar?

- Peão. 
- Quanto custa?

- R\$ 9.

- E para comprar todos esses (3)?

- $\mathrm{R} \$ 27$.

- Como você descobriu quanto dinheiro você precisava?

$-9 \times 3=27$.

- O que você gostaria de comprar?

- Mãozinha.

- Quanto custa?

- R\$ 1.

- E para comprar todos estes (5)?

- R\$ 5.

- Como você fez para descobrir quanto dinheiro você precisava?

$-5 \times 1$.

Nas primeiras intervenções e no pré-teste os estudantes utilizaram com dificuldades somente a adição para chegar ao resultado, no pós-teste verifica-se que já utilizam procedimentos mais elaborados de multiplicação. Para Macedo (2009, p.62), ao se deparar com as muitas possibilidades de desafio o estudante vai "[...] retirar e organizar esse conhecimento em sucessivos patamares, com base em uma experiência vivida, são ações ou operações necessárias. Sem elas, pode-se ter experiência, mas não se terá aprendizagem".

Na segunda situação da prova de divisão de granel, também verifica-se uma evolução nesse estudante.

- Quais dos objetos sobre a mesa daria pra você comprar com estas fichas (18) de tal maneira que não sobre e nem falte nenhuma ficha, mas que todos os objetos sejam iguais?

- 6 carrinhos ( $R \$ 3$ ). (contou as fichas separando em agrupamentos de dois em dois, depois de três em três até descobrir qual objeto poderia comprar).

- Como é que você sabe que dá para comprar 6 carrinhos?

- Contando o dinheiro de 3 em 3 aí descobri. 
- Pode escolher outro objeto, mas lembre-se não pode sobrar e nem faltar moedas e só pode comprar objetos iguais. Qual você vai comprar?

- 3 Chocalhos (R\$ 6).

- Como é que você descobriu que dá para comprar 3 chocalhos?

- Contando o dinheiro: $6+6+6$.

- Pode escolher outros objetos. Qual você vai comprar?

- 2 peões (R\$9).

- Como é que você descobriu que dá pra comprar 2 peões?

- 9 × 2 = 18 (contou com a ajuda dos dedos).

"B" não conseguiu chegar à conduta IV da divisão que corresponde às crianças que antecipam as possíveis composições do todo com os respectivos conjuntos equivalentes por meio de operações mentais, sem se basear em comprovações empíricas, mas evoluiu para a conduta III, que pressupõe os processos multiplicativos. No pré-teste ela não conseguiu concluir a atividade, dizia que não podia comprar nada que custasse mais de um real, não admitia a possibilidade de fazer diferentes composições, nem mesmo com conjuntos equivalentes.

Para chegar ao resultado, ainda utilizava procedimentos empíricos como somar nos dedos, utilizava rascunhos, mas já conseguia correlacionar o todo e as partes simultaneamente. Quando dividia, já conseguia fazer um tateio sistemático, compreendendo algumas propriedades, com possibilidades de distribuição do todo. Ela ia separando os objetos intuitivamente até acabar o número total de fichas: distribuiu 18 fichas, por 2, 3, 6 e 9 objetos. Considerando a situação inicial ela evoluiu significativamente.

No jogo dos palitos, foram dados 21 deles e pedido para que formasse a quantidade máxima de figuras utilizando três palitos para cada figura. "B" formou sete figuras. Foram dados mais nove palitos, totalizando 30 palitos, foi pedido para que formasse a quantidade máxima de figuras com quatro palitos, rapidamente ela percebeu que sobrariam 2 palitos e daria $4 \times 7$ e se fizesse $4 \times 8$ ela precisaria de mais dois palitos. Conseguiu chegar ao processo multiplicativo por cálculo mental sem nenhum procedimento empírico.

No início da intervenção, "B" demonstrava introversão, medo, timidez e retraimento, ao longo da intervenção ela foi visivelmente melhorando, relacionando-se melhor com o grupo de colegas. É possível que dois fatores tenham influenciado essa estudante: a participação ativa nos jogos e atividades e a interação social. Esses dois fatores foram importantes na evolução de "B" da conduta I de divisão, no início da intervenção, para a conduta III. 
Outro jogo utilizado na intervenção foi o chamado "atividades com dados". Esse jogo explora os conceitos de adição, multiplicação e divisão. Permite ao aluno realizar diferentes procedimentos: cálculo mental, conservação numérica, construção da multiplicação aritmética passando pelos procedimentos aditivos e multiplicativos até a reversibilidade completa necessária à divisão.

Participaram dessas atividades os alunos "D", "K" e "L". Iniciou-se com duas fichas. Os alunos deveriam colocar duas fichas para cada ponto que caiu do dado. Inicialmente os alunos tiveram dificuldades de entender o princípio multiplicativo, mas quando entenderam, gostaram muito do jogo. Passou-se então para 3 pontos. Eles deveriam colocar 3 fichas para cada ponto que tirou no dado. Inicialmente eles utilizaram 1 dado e depois 2 dados. Cada estudante trabalhava com um valor que tirava no seu dado.

Um dos alunos tirou 7 pontos nos dados,então ele iria trabalhar com $7 \times 3$ enquanto o colega (K) tirou 9 pontos nos dois dados. Perguntei a "K":

- Quantas fichas você tem no total?

$-27$.

- Como você descobriu?

- Eu contei assim. (Fez agrupamentos de 3 fichas e foi contando $3+3+3+3$ $+3+3+3+3+3$ nos dedos).

- E quantas vezes você contou o 3? Contou os agrupamentos e respondeu?

- 9 vezes.

Apesar do procedimento aditivo inicialmente utilizado por "K", ele começou a compreender que podia contar nas fichas quantas vezes ele colocou os agrupamentos de 3. Nas jogadas subsequentes esse aluno foi se desvencilhando do procedimento aditivo e utilizando cada vez mais o procedimento multiplicativo e com muita rapidez. De uma ação observável ele chegou a uma ação mental não observável. Quando é priorizada a ação do aluno sobre o objeto, ele consegue fazer inferências sobre os observáveis e relacionar as ações com os objetos. Esse grupo foi aos poucos fazendo cálculos, considerando o número de vezes que contavam os agrupamentos de fichas.

No segundo momento, fez-se a operação inversa. Foram colocadas 12 fichas, e eles deveriam descobrir os pontos do dado: que número deve ser tirado no dado para dar esse total. Inicialmente eles tiveram um pouco de dificuldade, mas logo perceberam a lógica e foram respondendo com rapidez, mesmo para os números maiores como 27, 21, 24, 18 divididos por 3. 
- Foram selecionadas 9 fichas? Que número eu tirei no dado?

- 3.

- Por quê?

- É $3 \times 3$.

- Tenho 18 fichas quantos pontos no dado eu tirei?

- 6.

- Por quê?

- É $6 \times 3$.

- Tenho 21 fichas que número tirei no dado?

- 7, mas precisa de dois dados pra tirar 7.

Foram acrescentadas as fichas em grupos de 3 até chegar ao $9 \times 3$. Mesmo procedimento com 4, 6, e 7 fichas.

Esses estudantes faziam o cálculo da divisão 21/3, 18/6, 9/3 e 24/4, mas, utilizando como referência a multiplicação. Os três alunos que participaram dessa intervenção saíram da conduta I de divisão para a conduta III. Em todas as situações foi lançado o seguinte contra argumento: um menino de outra sala disse que poderia dividir $21 / 3$ ou 18/6 o que você acha disso? Todos foram unânimes em dizer que estava certo, mas que era mais fácil fazer com a "conta de vezes". A influência da memorização da tabuada está bem presente nesse tipo de resposta.

O jogo chamado "Tigous" permite trabalhar simultaneamente as quatro operações. Participaram dessa intervenção os alunos "I", "K", "L". Eles jogaram com 2 dados inicialmente e quando os números ficaram maiores, aumentaram para 3 dados. Em determinada jogada, "I" fez 17 pontos somando os pontos dos três dados, mas não tinha 17 no tabuleiro, então ele começou a subtrair até chegar a um resultado que fosse compatível com o tabuleiro. Utilizaram a adição inicialmente, a subtração e somente no final começaram a utilizar a multiplicação. Não conseguiram realizar a operação de divisão para chegar ao resultado, somente a partir da segunda jogada. Uma das últimas casas a ser preenchida era o número 36, logo um dos alunos (L) lembrou-se do cálculo que fizera em outro jogo e disse: pode ser $6 \times 6$ ou 36 dividido por 6.

Todos os estudantes que participaram da intervenção evoluíram nas condutas de divisão. A evolução verificada não ocorreu somente quanto à divisão, verificou-se melhor compreensão da adição e multiplicação. Mesmo sendo alunos de uma mesma classe e idade, verificaram-se diferentes níveis iniciais de compreensão das noções de adição, multiplicação e divisão. 
Nos jogos de estratégia, os alunos foram aos poucos percebendo que poderiam impedir que o colega ganhasse se jogassem no local correto, com esse exercício eles se obrigavam a descobrir a jogada mais conveniente para impedir que o outro grupo ganhasse. Os jogos também requeriam dos alunos cálculos mais sofisticados e complexos, eles inicialmente utilizaram os dedos, mas à medida que jogavam se desvencilharam do suporte material e recorriam ao cálculo mental. É possível que a intervenção pedagógica foi capaz de provocar melhores condutas nas operações de divisão.

\section{Considerações finais}

Os métodos de ensino baseados na memorização e na reprodução mecânica não permitem o processo de aprendizagem considerando a construção do conhecimento e nem a coordenação das ações mentais por meio da abstração reflexionante. Os jogos, desafios, e situações problemas são fonte de desequilíbrios, para Piaget (1977, p. 23) "deve-se procurar nos desequilíbrios uma das fontes de progresso no desenvolvimento dos conhecimentos". Para Macedo (2009, p. 57):

Os desequilíbrios (insuficiências, contradições, conflitos marcados pela primazia das afirmações sobre as negações) são fontes de progresso. Isto é, as perturbações que produzem desencadeiam no sujeito a busca ativa, cuja orientação, para melhores formas (coordenações) ou conteúdos (observáveis) resultará como tendência, um melhoramento do nível atual de interação. Esta é uma das condições e, por extensão, um dos aspectos fortes de um jogo ou desafio.

Quando submetidos a situações com jogos e desafios, os alunos que participaram da educacional tiveram melhores condutas quanto à multiplicação e divisão, mesmo transcorridos menos de três meses de intervenção pedagógica. A construção da operação de divisão passa por patamares de equilíbrio. O ensino formal não garantiu a esses estudantes a construção dessa operação, é possível que a aprendizagem a que eles foram submetidos consistiu em experiências de memorização mecânica sem maior proveito cognitivo.

Muitos estudos como de Kamii (2015), Macedo, Petty e Passos (2005), Mantovani de Assis (2013) e Zaia, (2010) foram unânimes em afirmar que os jogos de regras favorecem o desenvolvimento dos aspectos físicos, as percepções, a inteligência, a criatividade, a espontaneidade, as relações sociais, entre outros. Crianças com dificuldades de aprendizagem vão, gradativamente, modificando a imagem negativa do ato de conhecer, tendo uma experiência em que aprender é uma atividade interessante e desafiadora. Os resultados dessa investigação nos permitem comprovar a eficácia 
dos jogos de regras, desafios e situações-problema nos processos de aprendizagem. Os resultados abrem uma discussão para o papel dos jogos usados no processo interventivo para a aprendizagem matemática nas escolas de ensino fundamental. Os jogos, desafios e situações-problema contribuem para o aprendizado dos alunos, porém é fundamental salientar que o desenvolvimento e aprendizagem não estão no jogo em si, mas no que é desencadeado a partir das intervenções e dos desafios propostos aos alunos e da mediação do professor.

$\mathrm{Na}$ aprendizagem de qualquer conteúdo escolar e não escolar é importante considerar o papel de quem aprende e de quem ensina. $\mathrm{O}$ aluno precisa formar uma compreensão do conceito, e por melhor que o professor ou o adulto explique um conteúdo, não é possível garantir a compreensão do aluno, porque a compreensão é um ato do aluno e a explicação é um ato do professor. Não é a aprendizagem de novos fatos ou elementos, mas é a construção única e individual daquele estudante de novos conceitos e novas compreensões.

As intervenções podem ser orais, questionamentos, solicitação de justificativas de jogadas, remontagem de um momento do jogo etc. É necessário que o educador sempre apresente novos obstáculos a serem superados a partir do que o estudante já sabe sem abandonar o aluno à sua própria sorte e à sua aprendizagem espontânea. Para Fioroti e Ortega (2009), quem ensina precisa saber como se processa a compreensão, que é o trabalho do aluno, para então organizar sua explicação, trabalho do professor. A compreensão envolve a interiorização, movimento em direção ao estudante, ao passo que a explicação se refere à exteriorização, movimento em direção ao objeto. No caso do professor, há uma interdependência entre essas duas ações, compreender e explicar, posto que a segunda demanda a primeira.

O fato de todos os estudantes que foram submetidos à intervenção obterem êxito em condutas mais evoluídas de divisão, quando submetidos a um processo de intervenção pedagógica ativa, evidencia que é possível remediar a situação de tantos estudantes que não aprendem. Ainda cabe aos educadores criar formas de intervenções através de situações prazerosas, nas quais o estudante possa se sentir motivado e confiante, em vez de simplesmente tentar substituir uma resposta tida como "errada", por outra também não compreendida pela criança, e os jogos de regras num contexto de interação social parecem ser ainda uma boa saída para os estudantes com ou sem dificuldades de aprendizagem e uma forma eficaz de diminuir o fracasso e o abandono escolar. 


\section{Referências}

CAMPELL, Donald; STANLEY, Julian. Delineamentos experimentais e quaseexperimentais de pesquisa. São Paulo: Edusp, 1979.

CORREA, Jane; MEIRELES, Elizabet. A compreensão intuitiva da criança acerca da divisão partitiva de quantidades contínuas. Revista: Estudos de Psicologia. v.5, n.(1), p. 11-31, 2000.

DAYAN, Silvia Parrat. A relação Parte/todo na Psicologia Piagetiana. Archives Jean Piaget. Universidade de Genebra. [SI]. 2015.

DURO, Mariana Lima; BECKER, Fernando. Análise Combinatória: do método

aleatório à combinatória sistemática. Revista Educação \& Realidade, Porto Alegre: v. 40, n. 3, p. 859-882, jul./set. 2015. http://dx.doi.org/10.1590/2175-623641714.

FIOROT, Meire; ORTEGA, Antonio Carlos. Modos de aprender e de ensinar de professoras em situações com o jogo traverse. In: MACEDO, Lino. (ORG) Jogos psicologia e educação. São Paulo: Casa do Psicólogo, 2009.

GRANELL, Carmem Gomez. Processos Cognitivos en Aprendizagem La da

Multiplicación.In: Montserrat Moreno y Equipo dellmipae. La Pedagogia Operatória - um enfoque constructivista de la educación. Barcelona: Editorial Laia, 1983.

INHELDER, Barbel; PIAGET, Jean. Da lógica da criança à lógica do adolescente. São Paulo: Livraria Pioneira, 1976.

KAMII, Constance. Crianças pequenas reinventam a aritmética. Porto Alegre: Artmed, 2002.

KAMII, Constance. Frações: encorajando estudantes do primeiro ano do EF a inventá-las e a realizarem operações de adição e subtração com elas. In: MOLINARI, Adriana. et al. (ORG). Novos caminhos para ensinar e aprender matemática. Campinas, Book, 2015.

KAMII, Constance; JOSEPH, Linda Leslie. Crianças pequenas continuam reinventando a aritmética. Porto Alegre: Artmed, 2008.

LACOMBE, Anna Maria. Acender um fogo - o jogo e o teatro na escola. Rio de Janeiro Edições pró saber, 2002.

MACEDO, Lino. Abstração e aprendizagem da matemática. In MOLINARI, Adriana. et al. (ORG) Aprender matemática e conquistar a autonomia. São Paulo: Book, 2014. 
MACEDO, Lino. Teoria da equilibração e jogo. In MACEDO, Lino. (ORG) Jogos, psicologia e educação. São Paulo: Casa do Psicólogo, 2009.

MACEDO, Lino; PETTY, Ana Lúcia; PASSOS, Nerimar Christe. Aprender com jogos e situações problemas. Porto Alegre: Artmed. 2000.

MACEDO, Lino; PETTY, Ana Lucia; PASSOS, Nerimar Christe. Os jogos e o lúdico na aprendizagem escolar. Porto Alegre: Artmed, 2005.

MANTOVANI DE ASSIS. Orly, Zucatto. Proepre Fundamentos Teóricos. 3a edição. Campinas: Book, 2013.

MANTOVANI DE ASSIS, Orly Zucatto; MOLINARI, Adriana Corder; ZAIA, Lia; RABIOGLIO, Marta; BESSA, Sônia. O desafio de ensinar e aprender matemática na educação básica. Campinas: Book, 2011.

MORGADO, Luiza. O ensino da aritmética: perspectiva construtivista. Coimbra: Livraria Almedina, 1993.

NUNES, Terezinha. et al. Introdução à educação Matemática: os números e as operações numéricas. São Paulo: Proem, 2001.

NUNES, Terezinha; BRYANT, Peter. Crianças fazendo matemática. Porto Alegre: Artes Médicas, 1997.

PIAGET, Jean. Abstração Reflexionante. Porto Alegre: Artes Médicas, 1995.

PIAGET, Jean. Observações sobre a Educação Matemática. In: MANTOVANI DE ASSIS, et al. (org) Educação Matemática: Uma contribuição para a formação continuada de professores. Campinas: Book, 2013b.

PIAGET, Jean. A Psicologia da Inteligência. São Paulo: vozes. 2013a.

PIAGET, Jean. O desenvolvimento do pensamento: equilibração das estruturas cognitivas. Lisboa: dom quixote, 1977.

PIAGET, Jean; INHELDER, Barbel. A Psicologia da criança. $5^{\text {a }}$ edição. Rio de Janeiro: Bertrand Brasil, 2011.

PIAGET, Jean; SZEMINSKA, Alina. A Gênese do número na criança. $3^{a}$ edição. Rio de Janeiro: Zahar, 1981.

VERGNAUD, Gerard. O longo e o curto prazo na aprendizagem da matemática. Educar em Revista, Curitiba, n. especial 1/2011, p. 15-27, 2011. http://www.scielo. br/pdf/er/nse1/02.pdf disponível em 15/06/2017. 
ZAIA, Lia Leme. Jogar para desenvolver e construir conhecimento. In: Jogar e aprender matemática. Campinas: Book, 2010.

Recebido em dezembro de 2016

Aceito em setembro de 2017

SONIA BESSA é doutora em Educação pela Universidade Estadual de Campinas

- UNICAMP, pós-doutora pela Universidade Federal do Triangulo Mineiro UFTM. Professora titular do Departamento de Educação da Universidade Estadual de Goiás. UEG. Membro do Laboratório de Psicologia Genética da Unicamp. Email: soniabessa@ gmail.com 